\title{
Gold in Electronic Components
}

\author{
NEW RESEARCH FINDINGS
}

\author{
Morton Antler \\ Bell Laboratories, Columbus, OH., U.S.A.
}

\begin{abstract}
The Electronic Components Conferences of the Institute of Electrical and Electronic Engineers constitute a forum for discussion of all aspects of modern electronic components: basic phenomena, device and materials characteristics, interconnections and manufacturing technologies. A recurring theme in San Diego, from 10th to 12th May, 1982, attention was focussed on conservation of gold in connectors, and in bonded and soldered interconnections. This review highlights significant developments in this area.
\end{abstract}

Gold is unique in combining high conductivity, corrosion resistance and excellent mechanical properties. Although more efficient utilization of the metal in electronic components is proving possible, for example by using it in smaller amounts in conjunction with other metals, experience is showing that it can rarely be replaced.

\section{Connectors}

The contacts of separable connectors have traditionally been made of gold and gold-rich alloys, such as cobalt-hardened electrodeposits. In order to reduce costs there is considerable interest in exploring alternative materials, especially less expensive noble metals like palladium. In most cases, however, degradation of contact properties such as electrical conductivity, durability in sliding applications and corrosion resistance occurs with materials other than gold. Nevertheless, by using some gold with a cheaper material, it may be possible to retain most of the desirable characteristics of all-gold systems. Several papers were presented at the conference which show ways of achieving this objective.

S.P. Sharma, E.S. Sproles, Jr., and F.E. Bader of Bell Laboratories, Columbus, Ohio, in 'Characterization of Inlay Materials', discussed 'diffused gold' materials designated DG $\mathrm{Pd}$ and DG R156. These are inlays of palladium and 60 palladium / 40 silver weight per cent alloy, respectively, which have been fabricated with an initial outer layer of gold having approximately 10 per cent of the thickness of the palladiumbased material. In processing the inlay, which involves successive rollings and heatings to obtain the desired final thickness and substrate temper, the gold and underlying metal interdiffuse to give a concentration gradient such as that illustrated in Figure 1 which was observed by Auger surface analysis with sputter depth profiling. The sample was nominally $1.25 \mu \mathrm{m}$ thick. Its surface composition, after removal of superficial contamination, was 54 per cent gold, 24 per cent palladium and 17 per cent silver. At a depth of $40 \mathrm{~nm}$, the gold content was 30 per cent. The significance of this new product is that its susceptibility to corrosion by reactive chlorine-containing compounds in the en- vironment at elevated relative humidity is markedly reduced when compared with that of the 60 palladium $/ 40$ silver per cent alloy. Its surface hardness $\left(246 \mathrm{~kg} / \mathrm{mm}^{2}\right.$ by the Knoop method with a load of $25 \mathrm{~g}$ ) is similar to that of the palladium-silver alloy without gold, thus ensuring good wear resistance. The gold is present in far greater depth than it would be if it were a distinct layer on the surface. Inlays locate the contact material to a stripe on the surface of the sheet material, and by stamping and forming so that the inlay is confined to the functional area, precious metal utilization is made especially efficient. DG R156 is used on certain types of connector contacts in Bell System telephone equipment.

Thin gold coatings on electrodeposited palladium may replace thicker gold coatings in separable connector contacts. I. Andoh, H. Koyama, S. Shioiri and M. Endo of Fujitsu Limited, Kawasaki, Japan, in 'Characteristics of PalladiumGold Sliding Contact on Connectors', proposed a finish consisting of $100 \mathrm{~nm}$ of gold on $600 \mathrm{~nm}$ of palladium. The behaviour of this composite was compared to that of a standard $750 \mathrm{~nm}$ thick gold finish on a widely used flat cable connector. A nickel underplate was employed in both cases. Testing was exhaustive, consisting of: durability evaluation on insertionwithdrawal, vibration and shock, high temperature soak, steady state humidity ageing, thermal shock, salt spray corrosion and ageing under an electrical load. Most of the procedures were in accordance with U.S. Military Standards. In addition, mated contacts were exposed to two corrosive environments consisting of $45 \mathrm{ppm} \mathrm{H}_{2} \mathrm{~S}$ and $10 \mathrm{ppm} \mathrm{SO}_{2}$ in air, respectively, at elevated relative humidity. It was found that the new contact finish was equivalent to the standard gold finish in most cases. Although the withdrawal force of the composite plating was somewhat higher, wear resistance (determined by estimating the area of exposed underplate and substrate following insertion and withdrawal cycles) was superior. The authors concluded that thin gold on palladium with a nickel underplate should be a satisfactory contact finish for electronic connectors.

Mated palladium contacts are prone to form frictional polymer when subjected to small relative movements (fretting) 
Fig. 1 Concentration/depth profile of Diffused Gold R156 inlay contact material. Gold in an initial layer, originally about $130 \mathrm{~nm}$ thick, has diffused into the 60 palladium $/ 40$ silver per cent underlying layer. The gold concentration is 54 per cent at the surface and 30 per cent at a depth of $400 \mathrm{~nm}$. The overall thickness of the sample is $1.25 \mu \mathrm{m}$

due to external vibrations, fluctuating temperatures and other causes. This contamination arises when organic air pollutants in the environment are adsorbed on the surface and polymerize during fretting. Contacts made of palladium or high palladium alloys may, therefore, be unsatisfactory. Gold connector contacts do not degrade in this way, for gold is nearly completely resistant to polymer formation. Since palladium has been proposed as a connector contact material, it was useful to determine whether opposing contact metals could be found which inhibit polymer formation. M. Antler of Bell Laboratories, Columbus, Ohio, in 'Fretting of Electrical Contacts: An Investigation of Palladium Mated to other Metals', studied the problem with a bench apparatus in which contact fretting could be simulated. Contact resistance was determined over small increments of distance across the wear track in experiments in laboratory air conducted under a load of 50 grams with a wipe length of $0.02 \mathrm{~mm}$ for 100000 cycles. One contact member was palladium and the other was varied.

It was found that contact resistance may be stable, may rise quickly to high values, may increase gradually to intermediate levels or may be stable until a wearout process occurs after which contact resistance rises. These behaviours were found to be a result of the film-forming tendency of the interface materials which, in turn, depended on the composition of the metals in the contact pair and their tendency to transfer during fretting. The composition of the interface of a dissimilar metal pait changed from the initiation of fretting until a state of equilibrium was attained in which both surfaces were identical. High contact resistance during fretting with a palladium contact can be avoided when the opposite member is a non- or lowpolymer forming metal such as gold, silver or alloys of these metals containing up to about one third palladium. A second condition is that the mating contact should be softer so that the direction of metal transfer is to the palladium. Finally, if the opposing material is a thin gold layer on a base metal or substrate that forms polymer, the gold thickness should be sufficient to resist wear-through during the service life of the connector. An

Fig. 2 Examples of rise in contact resistance during the fretting of solid palladium mated to cobalt-hardened gold electrodeposits and 70 gold/30 silver per cent clad materials. Gold transfers to the palladium, thereby converting the combination to an all-gold system having stable contact resistance. When the gold layer wears through, contact resistance rises. The thicker the gold, the longer will be the contact life

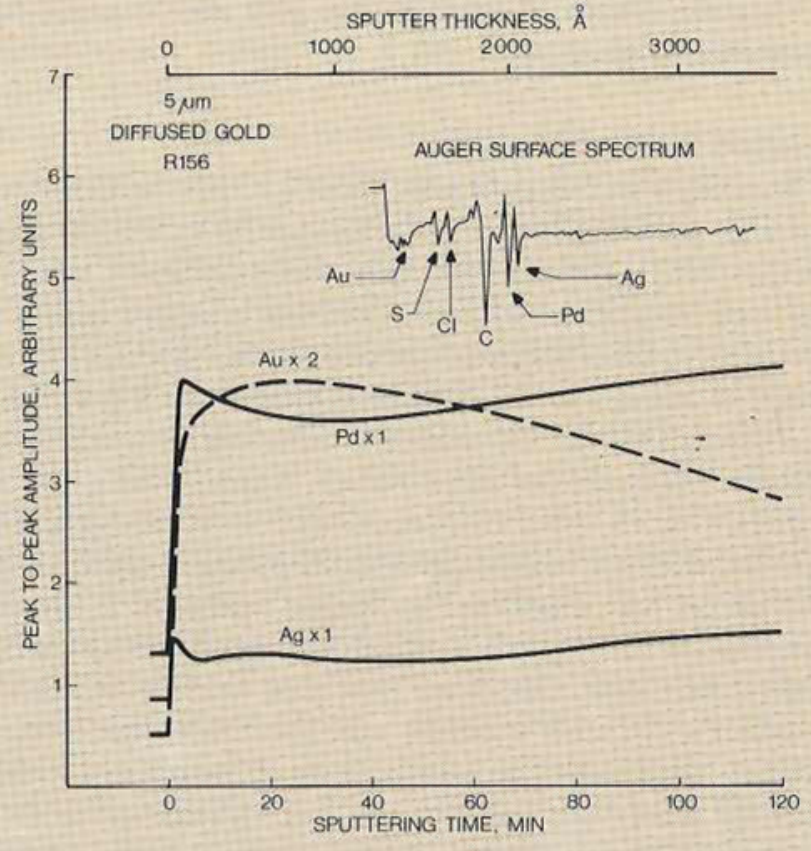

example of these findings is given in Figure 2 which compares the performances of gold-cobalt electrodeposits and a gold-rich alloy as counter materials for palladium. With the $600 \mathrm{~nm}$ gold finish (curve a) stable contact resistance was retained for ten times as many passes compared with all-palladium contacts before wear through. Thicker gold (curve d) was even better. Likewise, the 70 gold/ 30 silver per cent by weight alloy was a more satisfactory material when thick (curve c) than when thin (curve b). The value of these gold-containing materials is that

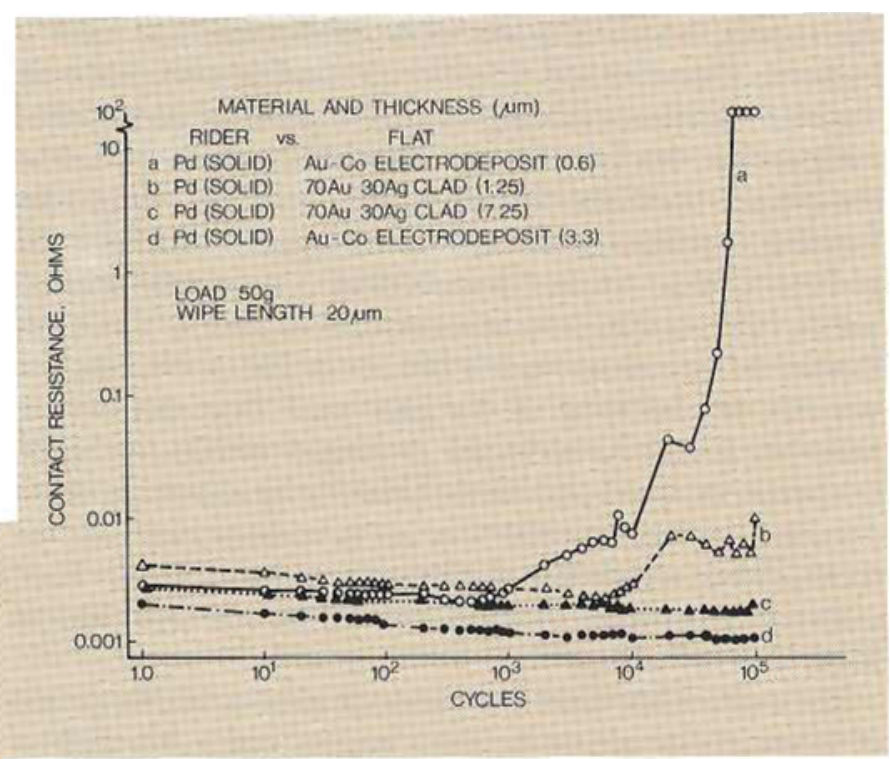


they transfer to the opposing palladium contact, thereby converting the system to an all-gold or gold alloy non-polymerforming configuration.

\section{Bonded Interconnections}

Bonding with fine gold wire, about $0.03 \mathrm{~mm}$ in diameter, is the most used interconnection technique for hybrid integrated circuits (HIC). This is usually done thermosonically, that is by applying ultrasonics with heat. Gold wire is pressed against the conductive path of the circuit the temperature of which has been raised to about $150^{\circ} \mathrm{C}$. Pressure is applied for a few tens of milliseconds with an automatic tool distorting the wire to form a ball that adheres to the circuit surface. A good bond is one having a pull force which is about equal to the tensile strength of the wire and does not weaken significantly during component life. The circuit may experience prolonged operation at elevated temperature with periodic thermal cycling and exposure to high relative humidity. Laboratory tests used to evaluate bonding variables and circuit materials take these facts into account. Copper-based thick film substrates are of interest as a replacement for more costly noble metals, but it is necessary to determine how they can be used and how reliable are the resulting gold wire bonds made to them.

V.A.Pitt and C.R.S. Needes of E.I. Du Pont de Nemours and Co., Inc., Wilmington, Delaware, studied 'Thermosonic Gold Wire Bonding to Copper Conductors'. They employed $12.5 \mu \mathrm{m}$ thick copper frit screen-printed onto a dielectric and fired in nitrogen. Gold wires were bonded within the range of conditions normally used for bonding them to thick film gold conductors. Pull strengths differed little when specimen bonding temperatures were in the range of 125 to $200^{\circ} \mathrm{C}$ for exposure times of 10 to 360 minutes. At lower stage temperatures, up to $75^{\circ} \mathrm{C}$, some difficulty in bonding was observed. Oxidation of the copper, which increases with temperature and time of exposure, therefore had no effect on bonding with gold wire. Another significant finding was that a glaze (of unidentified composition, but presumably nonmetallic) which formed on the copper thick film during initial firing did not inhibit bonding. Ageing of gold wire bonds to copper thick films at 150 and $250^{\circ} \mathrm{C}$ in air resulted in small reductions in pond strength within 100 hours $\left(20\right.$ per cent or less reduction at $250^{\circ} \mathrm{C}$ ) with no further changes on ageing to 3000 hours. The initial reduction was due to annealing of the gold wire. Degradation was, however, found to occur on prolonged storage at higher temperatures, bond pull strengths falling by an average of one third in 2000 hours at $300^{\circ} \mathrm{C}$ or in 750 hours at $350^{\circ} \mathrm{C}$. Spontaneous bond separations also began to occur at $300^{\circ} \mathrm{C}$. Thermal cycling between -55 and $+150^{\circ} \mathrm{C}$ for 100 cycles had no effect on bond strengths.

The authors discussed their results in terms of the formation of intermetallic phases between copper and gold, such as
$\mathrm{Cu}_{3} \mathrm{Au}, \mathrm{CuAu}$ and $\mathrm{CuAu}$. Copper diffuses more rapidly than gold, and prolonged exposure at high temperature can result in porosity, or Kirkendall voids, that weaken the gold/copper bond. Prior work has shown that diffusion and the development of porosity do not occur at a significant rate below $150^{\circ} \mathrm{C}$. Metallographic examinations coupled with X-ray determinations of copper concentration profiles across the interfaces of aged samples showed evidence of diffusion and of the presence of intermetallic phases after prolonged ageing at $250^{\circ} \mathrm{C}$ and higher, but porosity did not develop as readily as had been observed in other bonding studies. Grain size, the presence of impurities in the copper, and other factors have an influence on diffusion kinetics and the long-term qualities of wire bonds. Gold wire bonds to copper thick films can therefore be made which are reliable in severe service conditions.

Another study of gold wire thermosonic bonding to a copperbased material was presented by J. Fistor, J. Breedis, and J. Winter of Olin Corporation, New Haven, Connecticut, under the title 'Gold Lead-Wirc Bonding of Unplated C194'. As is the case with thick film materials, there is interest in reducing precious metal usage on lead frames, and these authors studied bonding directly to an unplated half-hard frame alloy, C194 (97 copper minimum / 2.53 iron / 0.03 phosphorus / 0.12 zinc weight per cent). Surface finish, cleanliness and removable protective coatings for extending lead frame shelf life were evaluated. A commercial bonder was used with a stage temperature of $180^{\circ} \mathrm{C}$. Bond strengths were determined by pull tests. The $\mathrm{C} 194$ alloy was cleaned with solvents to remove oils, followed by brief immersion in dilute sulphuric acid. Shelf storage prior to bonding was simulated by 28 days of ageing in an office environment. It was found that the percentage of satisfactory bonds and the bond strengths were equivalent to those obtained with a gold-plated lead frame material, provided exposure at $180^{\circ} \mathrm{C}$ did not exceed $175 \mathrm{~s}$ (usually exposure times at this temperature were about $12 \mathrm{~s}$ with the equipment that was used). Lower stage temperatures did not give satisfactory bonds. Substrates having a matte finish were more difficult to attach successfully than those which were smooth, because the cleaning procedure did not completely remove contaminants. Coatings used to inhibit tarnish (and intended to prolong permissible storage time between cleaning and bonding), such as tolyltriazole, a phosphonic acid treatment, and one obtained from a vapour phase inhibiting packaging material, degraded bonding efficiency relative to unprotected specimens. The authors concluded that gold wire bonding to an unplated copper-based lead frame material is possible provided cleaning is thorough, storage prior to bonding is brief and recommended bonding procedures are carefully followed.

Gold wire bonds to aluminium conductors and aluminium wire bonds to gold conductors are both used in semiconductor devices. It is known that in service at normal operating 
temperatures of 75 to $150^{\circ} \mathrm{C}$, ageing can increase electrical resistance, lower bond strength, and even result in spohtaneous separation. This occurs by the formation of voids near the interface, which are caused by differences in the rates of interdiffusion of the two metals and also by the formation of brittle goldaluminium intermetallic compounds. Earlier studies conducted above $200^{\circ} \mathrm{C}$ did not suggest that this type of degradation could occur at the lower, actual operating temperatues. It was of interest, therefore, to establish the mechanisms of failure of gold-aluminium contacts using aluminium wires joined to gold and gold wires joined to aluminium when aged at a range of temperatures.

P.V. Plunkett and J.F. Dalporto of Sandia National Laboratories, Albuquerque, New Mexico, in 'Low Temperature Void Formation in Gold-Aluminum Contacts', studied the systems at temperatures ranging from 125 to $300^{\circ} \mathrm{C}$. In the case of ultrasonically made bonds between 99 aluminium $/ 1$ silicon per cent alloy wire and $6 \mu \mathrm{m}$ thick evaporated gold metallizations on alumina substrates, it was found that failure occurred much more readily on ageing at 125 or $150^{\circ} \mathrm{C}$ than at 225 or $300^{\circ} \mathrm{C}$. Significant changes occurred between 200 and 500 hours at $150^{\circ} \mathrm{C}$ and between 500 and 800 hours at $125^{\circ} \mathrm{C}$. SEM photographs of the wire bonds showed that at 225 and $300^{\circ} \mathrm{C}$ there was thinning of the wire above the heel of the bond, caused by aluminium diffusion; reduction in cross-section lowered bond strength. However, after ageing at 125 or $150^{\circ} \mathrm{C}$, the aluminium wire could be pulled out of the gold leaving a cavity, which is a more serious type of degradation than that which occurred at the higher temperatures. These failures were caused by voids between a gold-rich intermetallic phase and the pure gold of the substrate. The intermetallics penetrated $3 \mu \mathrm{m}$ below the original bond interface, and were therefore within the $6 \mu \mathrm{m}$ thick gold layer. At $225^{\circ} \mathrm{C}$, gold-aluminium intermetallics entirely consumed the gold layer and were found to be attached to the underlying metal before voids could form.

The practical consequence of these changes is that for a given surface temperature, there is a maximum gold thickness that should not be exceeded in order to prevent void formation. This was verified by experiment with $2 \mu \mathrm{m}$ thick gold metallizations which remained strong after 1000 hours of ageing at $150^{\circ} \mathrm{C}$. The distance of voids from the original interface increased with temperature. For example, at $300^{\circ} \mathrm{C}$ they occurred about $14 \mu \mathrm{m}$ below the original bond interface to aluminium wire. A summaty of the precautions needed to eliminate void formation is: minimize gold layer thickness and, as established by prior studies, prepare metallizations with impurity elements such as palladium, platinum and silver. Because bond design (processes, temperatures, purity of the metals and gold thickness) as well as operating temperature influence reliability, qualification tests should be conducted using the actual materials and realistic ageing temperatures (as opposed to the high temperatures in accelerated tests).

In the second part of the study, gold wires were thermosonically bonded to $1 \mu \mathrm{m}$ thick pads of the same aluminium-silicon alloy on silicon chips. Two types of chips were used which differed in the method of die mounting. Ageing of epoxy-attached samples at $150^{\circ} \mathrm{C}$ gave degraded electrical resistance and pull strengths after 100 hours and complete failures after about 600 hours. Eutectically-attached chips showed virtually no changes on ageing for 1000 hours. There was a similar difference in quality of the bond with gold wire on ageing at $300^{\circ} \mathrm{C}$, the eutectically-attached die configuration being much better. Cross-sectioned samples showed voids in the aged epoxy mounts, while none were found in the eutectically-attached samples. Auger analysis of low strength bonds pulled from samples with the epoxy mounting revealed high concentrations of carbon and chlorine in the fractured area. The authors concluded that thin aluminium metallizations give good bonds to gold wire provided contaminants from the epoxy curing are absent. Contaminants either accelerate void formation or, more likely, lead to corrosion of the sample. Additional experiments were performed which showed that plasma cleaning of the die prior to bonding eliminated the early failures at $300^{\circ} \mathrm{C}$, which is consistent with those of earlier studies.

\section{Soldered Interconnections}

Thin film conductors have multilayered structures, generally with the outermost being gold because of its high conductivity, nobility, ready wettability by 60 tin/ 40 lead weight per cent solder, and ease with which thermocompression bonds can be made to it. Since gold dissolves quickly in molten solder, undercoats are used. Some typical HIC conductor structures are shown in Figure 3. In many applications, external clip-on terminals are soldered to the circuit to provide electrical connection. High mechanical strength, of the order of $2.2 \mathrm{~kg}$ minimum, retained for as long as 40 years at $90^{\circ} \mathrm{C}$, is required for the joints to be considered satisfactory. Pull tests of soldered terminals before ageing generally show tearing within the solder, while failure at the thin film conductor/solder or terminal/solder interfaces is observed after ageing. Reduction of joint strength is caused by intermetallic compound formation involving tin with either gold, copper or palladium, depending on the joint geometry and structure of the thin film. H.N. Keller of Bell Laboratories, Allentown, Pennsylvania, in 'Significant Features of Solder Connections to Gold-Plated Thin Films', described a study of terminal design and material factors that control bond strength. Various phosphor-bronze terminals soldered to thin films on ceramic substrates were heated in ovens at temperatures up to $170^{\circ} \mathrm{C}$; forces required to cause failure were determined by pull testing after increasing ageing times, and bond interfaces were investigated by chemical and metallographic analyses. 

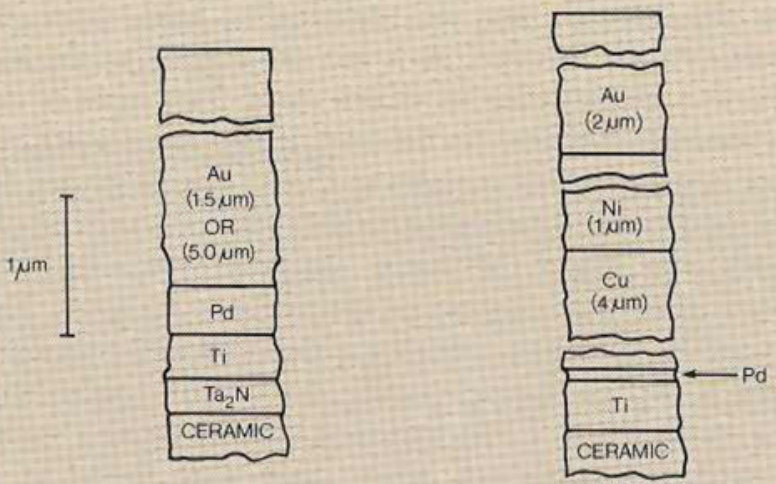

Fig. 3 Typical hybrid intergrated circuit film structures. Multiple layers are deposited on a ceramic substrate, the outermost being gold. Gold is an ideal material for this purpose, because of its high conductivity and corrosion resistance, and the ease with which it can be bonded by thermocompression and soldering methods
Lifetimes were shown to be determined by several interrelated factors: intermetallic formations, joint geometries, and time and temperature ageing conditions. Models of cross-sections after ageing and pull testing are shown in Figure 4 which illustrate the form of the fractures from representative solder joints and the complex intermetallic structures which can result. Separation usually occurred within the gold and palladium-tin or copper-tin intermetallics, depending on joint geometry. It was concluded that ideal terminations have large surfaces between the clip and the film termination, a large volume of solder, and mechanical designs which require that a U-shaped formed section (Figure 4, inset) of the terminal be straightened before external stresses can be applied to the joint.

Hybrid microelectronic circuits are made by fusing screenprinted paths of a 'thick' (greater than $12.5 \mu \mathrm{m}$ ) film conductor on an alumina substrate and subsequently attaching components to it with 50 indium/50 lead per cent solder. A commonly used thick film material is a mixture of pure gold powder with glass frit and additives which, on firing, bonds to the alumina both by mechanical interlocking and through compound formation at the interface. R.W. Gehman, G.A. Becka

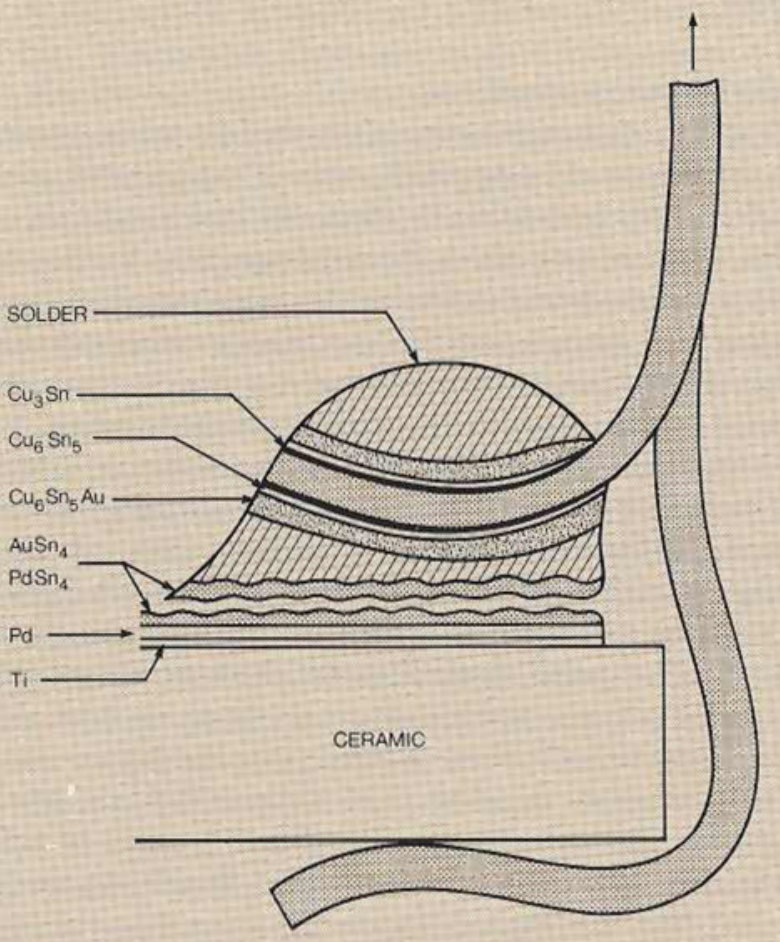

(a) SINGLE SIDED CIRCUIT

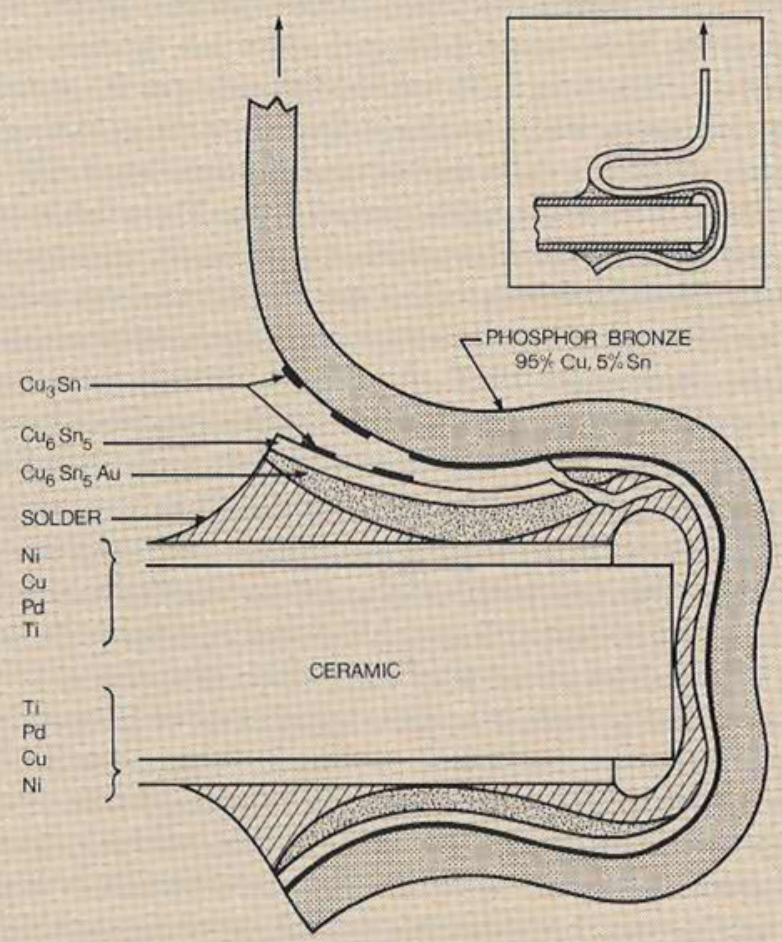

(b) DOUBLE SIDED CIRCUIT

Fig. 4 Model of solder joint cross-sections of the structures in Figure 3 aiter pull testing. Separation usually occurs within the brittle intermetallic compounds that form during thermal ageing prior to testing. Inset illustratesformed section in one design of terminal 
and J.A. Losure of Bendix Corporation, Kansas City, Missouri, in "Effects of Rework on Adhesion of PbIn Soldered Gold Thick Films', analyzed failures which could occur when cadmium oxide-containing gold-based conductor material was repeatedly teworked, as may occur during manufacture when defective components are removed and replaced. The cadmium oxide forms a strong spinel with alumina. By analysis of failed circuits (the gold films were $0.02 \mathrm{~mm}$ thick and testing involved heating the solder for 2 minutes at $250^{\circ} \mathrm{C}$ ), it was found that indium from the solder had diffused through the gold to the substrate where it had reduced the cadmium oxide of the spinel to free cadmium. A brittle intermetallic having the suggested formula, $\mathrm{Au}_{0} \mathrm{In}_{4}$, had also formed. Nevertheless, it was estimated that two reworks may safely be made with this system before bond strength is seriously affected. Thicker gold conductors can be reworked more than twice.

A widely used thick film electrode material is a paste of 80 silver/20 palladium per cent by weight. When in contact with tin-rich molten solders, intermetallics of palladium with tin form, leaving behind free silver. In sulphiding environments, such as those containing free sulphur, thinning of the electrode can occur by tarnishing and formation of silver sulphide, and this may eventually lead to electrical discontinuity. Two papers by authors affiliated to IBM addressed this problem: G. DiGiacomo, J. Gniewek, J. Rizzuto and W. Rosenberg in 'AuAgPd Ternary Alloy for Thick Film Electrodes', and V.C.
Marcotte and N.G. Koopman in 'Metallurgical Reactions of AgAuPd Electrode Paste with High Pb Solder', considered, respectively, the tarnishing kinetics and metallurgy involved in a new paste of composition 60 silver $/ 20$ gold $/ 20$ palladium per cent. Although depletion of palladium by solder could occur, the remaining material, 75 silver $/ 25$ gold per cent, is several orders of magnitude less reactive to sulphur vapour than is pure silver. Tarnishing in the field, assuming a pollution level of 0.1 $\mathrm{ppb}$ sulphur, requires over $2.8 \times 10^{4}$ years for a $0.01 \mathrm{~mm}$ thick conductor to be consumed. The recommended gold-containing paste is interchangeable with the original material in its screenprinting, firing temperature and other processing conditions.

\section{Summary}

Gold-containing materials are desirable in most separable electronic connectors, in wire bonding and in thick film soldered interconnections. However, costing reductions can be made by employing less gold or by combining it with other materials. Recent research into the characteristics of new systems provides assurance that there need be no loss in component performance and reliability when gold is more efficiently used.

\section{Reference}

'Proceedings of the 32nd Electronic Components Conference' San Diego, CA., May 10-12, 1982, Institute of Electrical and Electronic Engineers, New York, Cat. No. $82 \mathrm{CH} 1781-4$ 